\title{
Prevalence of six amoeba species colonising the gills of farmed Atlantic salmon with amoebic gill disease (AGD) using qPCR
}

\author{
Chloe J. English ${ }^{1,2, *}$, Fiona Swords ${ }^{3}$, Jamie K. Downes ${ }^{3}$, Neil M. Ruane ${ }^{3}$, \\ Natasha A. Botwright ${ }^{4}$, Richard S. Taylor ${ }^{5}$, Andrew C. Barnes ${ }^{1}$, James W. Wynne ${ }^{5}$, \\ Paula C. Lima ${ }^{4}$, Mathew T. Cook ${ }^{4}$ \\ ${ }^{1}$ School of Biological Sciences, The University of Queensland, Brisbane, QLD 4072, Australia \\ ${ }^{2}$ CSIRO Agriculture and Food, Aquaculture, Bribie Island Research Centre, 144 North Street, Woorim, QLD 4507, Australia \\ ${ }^{3}$ Marine Institute, Rinville, Oranmore, H91 R673 Co. Galway, Ireland \\ ${ }^{4}$ CSIRO Agriculture and Food, Aquaculture, Queensland Biosciences Precinct, 306 Carmody Road, St Lucia, QLD 4067, Australia \\ ${ }^{5}$ CSIRO Agriculture and Food, Aquaculture, Castray Esplanade, Battery Point, TAS 7004, Australia
}

\begin{abstract}
Amoebic gill disease (AGD) is the primary health concern for Atlantic salmon Salmo salar farmed in Tasmania, Australia. Neoparamoeba perurans is the aetiological agent of AGD; however, a diversity of other amoebae colonise the gills, and their role in AGD is unknown. Previous studies which document these accompanying amoebae on AGD-affected farmed Atlantic salmon relied on culture-based techniques which do not accurately determine the prevalence and abundance of these species nor whether they correlate with AGD pathology. Drawing on our previous culture-based study, here we develop and apply 5 new Taqman quantitative PCR (qPCR) assays to profile the prevalence of multiple amoeba species on the gills of AGD-affected Atlantic salmon held at 2 Tasmanian farm sites over a $1 \mathrm{yr}$ period. The prevalence and abundance of $N$. perurans was also assessed using a previously established qPCR method. N. perurans was the dominant species, and its abundance positively correlated with the progression of gross gill pathology. Only a small number of sporadic detections of Pseudoparamoeba and Vannellida species were observed. Nolandella spp. was the notable exception, as it was the most prevalent amoeba $(92 \%)$ at 1 site at 1 sample time, during which no $N$. perurans were detected on gills but low levels of gross gill pathology were observed. $N$. perurans is the predominant species and primary pathogen of AGD; however, there were instances when they were not detected on diseased gills and Nolandella spp. were highly prevalent. The significance of Nolandella spp. in relation to AGD is not yet understood.
\end{abstract}

KEY WORDS: Neoparamoeba $\cdot$ Nolandella $\cdot$ Amoebozoa $\cdot$ AGD $\cdot$ Taqman qPCR Atlantic salmon

\section{INTRODUCTION}

Gill health is fundamental to the success of finfish aquaculture. These delicate organs are responsible for gas exchange, acid-base balance, waste excretion and osmoregulation, yet are constantly exposed to a variety of microorganisms and environmental insults which can result in various gill diseases (Evans 2005,

\footnotetext{
${ }^{*}$ Corresponding author: chloe.english@csiro.au
}

Mitchell \& Rodger 2011). While the aetiologies of many disease pathologies are attributed to single pathological agents, the drivers of gill disease can be more complex (Gjessing et al. 2017, Herrero et al. 2018). A multifactorial approach to disease occurrence that considers the impact of environmental factors and microbial community structure, rather than focusing on a single agent, may therefore be a ra-

() The authors 2019. Open Access under Creative Commons by Attribution Licence. Use, distribution and reproduction are unrestricted. Authors and original publication must be credited. 
tional approach to gain a better understanding of disease in marine ecosystems (Egan \& Gardiner 2016) and, in this case, gill disease.

Amoebic gill disease (AGD) is a globally significant disease in marine aquaculture and remains the main health issue challenging Atlantic salmon Salmo salar aquaculture in Tasmania, Australia. AGD is caused by Neoparamoeba perurans (syn. Paramoeba perurans; Feehan et al. 2013), a free-living protozoan ectoparasite which colonises the gills of Atlantic salmon in the marine phase of production (Young et al. 2007, Crosbie et al. 2012). Attachment of $N$. perurans causes lamellar fusion, epithelial hyperplasia, oedema and ultimately mortality when left untreated (Adams \& Nowak 2001). While it is understood that salinity, water temperature and stocking density play a role in AGD prevalence and severity (Oldham et al. 2016), all the drivers of infestation and correlates of the associated gill pathology are not yet understood. This could contribute to inefficiencies in disease prediction and control during Atlantic salmon marine grow-out.

In addition to $N$. perurans, a diversity of other amoeba species colonise the gills of AGD-affected Atlantic salmon, with up to 11 other species having been isolated from farmed salmon in Tasmania, including the species of the genera Paramoeba, Vexillifera, Pseudoparamoeba, Vannella and Nolandella (Howard 2001, English et al. 2019). However, it is not understood whether these accompanying amoeba species are parasitic or commensal or if changes to the Amoebozoan community structure influence disease onset or progression. Moreover, the seasonal abundance of these amoebae and whether their presence correlates with AGD prevalence and severity of pathology is also unknown. Previous studies of gillassociated Amoebozoa identified the amoebae after isolating and culturing in vitro (Howard 2001, Bermingham \& Mulcahy 2007, English et al. 2019). These methods likely generate a skewed assessment of infection prevalence and abundance because they are biased towards amoebae that are more capable of growing in the chosen culture conditions. A more accurate, sensitive and high-throughput technique for detecting and quantifying particular microorganisms is quantitative PCR (qPCR) (Purcell et al. 2011). There are 3 published qPCR assays for speciesspecific detection of N. perurans (Bridle et al. 2010, Fringuelli et al. 2012, Downes et al. 2015). These assays are versatile tools for research, being used to answer a variety of AGD-related questions, including retrospective validation that $N$. perurans was the main causative agent in the earliest AGD outbreaks in Ireland (Downes et al. 2018) and confirmation that
Atlantic salmon can be experimentally infected from lumpfish Cyclopterus lumpus, a cleaner fish which is often cohabitated with farmed salmon to control sea lice (Haugland et al. 2017). Despite these assays being highly informative and adaptable tools for disease and ecological research, there are no qPCR assays designed for the variety of other marine amoebae which colonise AGD-affected fish.

In a recent study, we described $18 \mathrm{~S}$ rRNA sequences from many of the amoebae which colonise Atlantic salmon gills in Tasmania (English et al. 2019). These sequences are ideal for developing molecular detection assays which can be used to explore the potential role the Amoebozoan community plays in AGD onset and severity. Here, we design and validate 5 new amoeba qPCR assays using these 18S rRNA sequences. These assays, along with an existing $N$. perurans assay (Downes et al. 2015), were then used to assess amoeba prevalence and abundance on the gills of farmed Atlantic salmon over a 1 yr period from 2 different farm sites. This longitudinal survey aimed to identify relationships between specific amoeba taxa and farm sites, time points and gross gill pathology.

\section{MATERIALS AND METHODS}

\subsection{Gill swab sample collection}

Every 3 mo, from May 2017 to February 2018, during routine commercial gill checks at Tassal Operations Tasman and Killala leases (Fig. 1), large groups of Atlantic salmon Salmo salar were seined and crowded to ensure the fish were haphazardly mixed, then 40 fish were sampled from the crowd. The 2 farm sites have contrasting environmental conditions, with the Tasman lease being more oceanic, located closer to open water, and the Killala lease more brackish, located in the lower Huon Estuary. The average monthly water temperature and salinity at $5 \mathrm{~m}$ before each sampling event was obtained from Tassal Operations.

During sampling, fish were anaesthetised with 15 ppm of AQUI-S, then their gross gill pathology was scored according to Taylor et al. (2009) on a scale of zero (no gross lesions) to 5 (lesions covering $>50 \%$ of gill surface). All 16 gill surfaces were then swabbed (Westlabs) in situ, with one swab used for the left gill arches and one for the right arches to maximize the DNA yield. The left and right swabs for each fish were pooled and stored in RNALater (Ambion) at room temperature for a minimum of $2 \mathrm{~d}$ and then at $-20^{\circ} \mathrm{C}$ until processed for DNA extrac- 

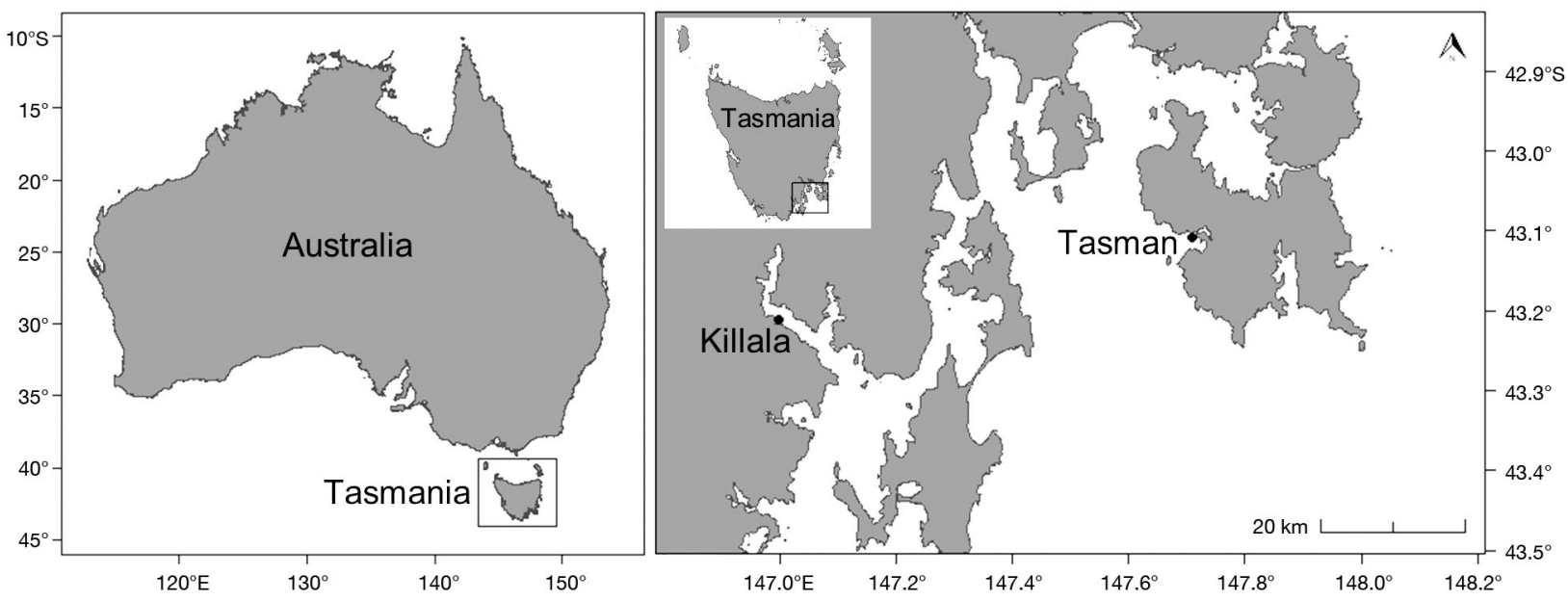

Fig. 1. Atlantic salmon sea pen sites, Killala and Tasman, sampled during the survey

tion. Other information collected included months since the fish were transferred to sea, the average fish weight and the number of days since the fish were last treated for AGD (2 to $3 \mathrm{~h}$ freshwater bath). The case history of each sampling event is summarised in Table 1. All sampling events occurred as planned apart from February 2018 at Killala as the site was de-stocked as part of standard commercial operations. Sampling of 280 salmon in this study was approved by the CSIRO Queensland Animal Ethics Committee (AEC number 2017-16).

\subsection{DNA extraction from gill swabs}

DNA was extracted from the preserved gill swab samples using a plate-based DNeasy Blood and Tissue Kit (QIAGEN) according to the manufacturer's instructions. Extracted DNA was quantified with a Nanodrop ND-1000 spectrophotometer (Life Technologies), then a working stock (30 $\mathrm{ng}^{-1} \mathrm{l}^{-1}$ ) of each sample was prepared using an epMotion 5070 liquidhandling robot (Eppendorf) and stored at $-20^{\circ} \mathrm{C}$.

\subsection{TaqMan qRT-PCR assay design}

Five TaqMan MGB probes and PCR primer sets were designed based on the 18S rRNA gene sequences of amoebae previously isolated from AGDaffected Atlantic salmon (English et al. 2019). The chosen amoebae for assay design included Nolandella sp. (strain MX5, accession number MH535951), Pseudoparamoeba sp. (MX1, MH535967), Paramoeba eilhardi (106KRT, MH535952), Vannellida C2 (149SVA, MH535956) and Vannellida C3 (136SVA, MH535954). From here on, these assays, in the order listed above, will be referred to as Nol, Pse, ParE, VanC2 and VanC3. Based on an alignment of 18S rRNA gene sequences from these species and Neoparamoeba perurans (MH535959), the primer and probe sets were designed on Primer Express 3.0.1 (Life Technologies) according to the guidelines. Before ordering the probes, the amplicon derived from PCR using each primer set was sequenced according to English et al. (2019) to confirm the correct sequence was being amplified. Primers were ordered from GeneWorks and probes from Thermo Fisher

Table 1. Case history of sampled Atlantic salmon. NA: no samples could be collected at that sampling event

\begin{tabular}{|c|c|c|c|c|c|c|}
\hline Farm site & Sample time & $\begin{array}{l}\text { Months since } \\
\text { ocean transfer }\end{array}$ & $\begin{array}{l}\text { Average fish weight } \\
(\mathrm{g})\end{array}$ & $\begin{array}{l}\text { Days since last } \\
\text { freshwater bath }\end{array}$ & $\begin{array}{l}\text { Water temp at } 5 \mathrm{~m} \\
\left({ }^{\circ} \mathrm{C}\right)\end{array}$ & $\begin{array}{c}\text { Salinity at } 5 \mathrm{~m} \\
\text { (ppt) }\end{array}$ \\
\hline Killala & $\begin{array}{l}\text { May } 2017 \\
\text { Aug } 2017 \\
\text { Nov } 2017 \\
\text { Feb } 2018\end{array}$ & $\begin{array}{c}1 \\
3 \\
7 \\
\text { NA }\end{array}$ & $\begin{array}{c}225 \\
719 \\
2530 \\
\text { NA }\end{array}$ & $\begin{array}{c}\text { no bath } \\
25 \\
64 \\
\text { NA }\end{array}$ & $\begin{array}{l}13.6 \\
11.9 \\
14.7 \\
\text { NA }\end{array}$ & $\begin{array}{l}31.7 \\
31.9 \\
31.1 \\
\text { NA }\end{array}$ \\
\hline Tasman & $\begin{array}{l}\text { May } 2017 \\
\text { Aug } 2017 \\
\text { Nov } 2017 \\
\text { Feb } 2018\end{array}$ & $\begin{array}{c}11 \\
3 \\
7 \\
10\end{array}$ & $\begin{array}{c}2365 \\
639 \\
1618 \\
2734\end{array}$ & $\begin{array}{l}48 \\
35 \\
37 \\
50\end{array}$ & $\begin{array}{l}12.1 \\
10.2 \\
15.5 \\
17.5\end{array}$ & $\begin{array}{l}34.5 \\
31.1 \\
32.0 \\
31.8\end{array}$ \\
\hline
\end{tabular}


Scientific. The optimum probe and primer concentration for a single-plex assay was then determined with a series of experiments following the Thermo Fisher Scientific standard protocols using amplicon-specific plasmid DNA as template (Thermo Fisher 2010). The amplicon-specific plasmid DNA was generated as described previously (English et al. 2019).

\subsection{Validation of reaction efficiency, sensitivity, specificity and reproducibility}

Assay validation was performed according to Downes et al. (2015) and Bustin et al. (2009). The following procedures were conducted separately on each of the 5 qPCR assays. To determine the efficiency of the assays, amplicon-specific plasmid DNA was serially diluted 10-fold and amplified in quadruplicate qPCR reactions. Only dilutions that provided a cycle threshold $(\mathrm{Ct})$ value in all replicates were used to generate a standard curve. Amplification efficiency was calculated based on the Ct slope method $\left(\right.$ Efficiency $\left.=\left[10^{(-1 / \text { slope })}\right]-1\right)$, and the linearity was demonstrated with the coefficient of determination $\left(\mathrm{R}^{2}\right)$. The equivalent number of $18 \mathrm{~S}$ rRNA copies corresponding to each standard curve was then determined by measuring the concentration of the plasmid DNA with a NanodropND-1000 spectrophotometer (Life Technologies) and then submitting this value and the length of the amplicon insert and vector to the DNA copy number calculator (Staroscik 2004). The 10-fold dilution series was then used to determine the limit of detection (LOD) for each assay. For this purpose, the lowest dilution that provided a $\mathrm{Ct}$ value in all replicates underwent a 2-fold dilution and was tested in quadruplicate. The mean of the lowest dilution of the 2 -fold dilution that provided a $\mathrm{Ct}$ value in all replicates was deemed the LOD. This sample was further analysed 20 times to assess the precision of the assay with $95 \%$ confidence.

The specificity of primers and probes were theoretically assessed using NCBI nucleotide Basic Local Alignment Search Tool (BLASTn) to identify potential non-target amplification of other amoebae and protozoans that colonise the gills of marine fish. The actual specificity was assessed by testing the assays against 7 in-house amoeba cultures previously isolated from AGD-affected Atlantic salmon gills ( $N$. perurans strain MP2, Vexillifera sp. strain MX6, Pseudoparamoeba sp. strain MX1, Vannella sp. strain MV3, MV4 and MV5 and Nolandella sp. strain MX5) (English et al. 2019) and 4 amoeba cultures obtained from American Type Culture Collection (ATCC) $(N$. pemaquidensis ATCC ${ }^{\circledR} 50172$ TM, Acanthamoeba jacobsi ATCC ${ }^{\circledR} 30732$ TM, Nolandella sp. ATCC ${ }^{\circledR}$ PRA-27 TM and Hartmannella vermiformis ATCC ${ }^{\circledR}$ 30967 TM).

The reproducibility of each assay was assessed by testing 10 gill swab DNA samples in triplicate on 3 consecutive days. These samples had previously tested positive for the target amoeba in preliminary experiments. The reproducibility was analysed by the coefficient of variation for intra- and inter-assay variation. The inter-assay differences were also assessed with a 1-way ANOVA. All qPCR validation experiments had the appropriate controls, including positive control and no-template negative control.

\subsection{Inhibition}

To determine whether any amplification inhibitors were present within the gill swab DNA, 5 gill swabs were diluted 2-fold 7 times such that the highest con-

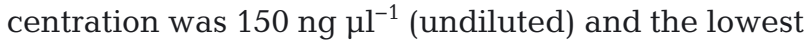
was $2.34 \mathrm{ng} \mathrm{\mu l}^{-1}$ (1/64 dilution). All dilutions had a working stock volume of $10 \mu \mathrm{l}$. Each of the diluted samples were then spiked with $0.008 \mathrm{ng}$ of plasmid DNA specific to the existing $N$. perurans assay (NPJ) (Downes et al. 2015). Templates (1.8 $\mu$ in $5 \mu l$ reaction) from each of the spiked dilution series were then tested in triplicate according to the qPCR protocol outlined by Downes et al. (2015).

\section{6. $q P C R$ analysis of gill swab survey}

To quantify the relative abundance of several amoeba taxa on the gills of farmed Atlantic salmon, the 5 newly designed and 1 previously published qPCR assay was performed on the gill swabs collected from farm sites. Template (30 ng) DNA was tested in $5 \mu \mathrm{l}$ reactions using MyTaq ${ }^{\mathrm{TM}}$ DNA Polymerase (Bioline) with 3 technical replicates across a 384 well PCR plate. DNA was amplified using a ViiA $^{\text {TM }} 7$ Real-Time PCR Machine (Applied Biosystems) with the thermal cycling conditions specific for each assay (Table 2). A 10-fold dilution series of plasmid DNA specific to the amplicon of each assay, with a known copy number, was amplified on each plate to generate a standard curve used to determine the copy number of each sample. Each plate also included a positive control, a negative control and a negative-process control (a blank sample extracted along with the gill swab samples). An external process control (salmon elongation factor-1 $\alpha$ ) was also 
Table 2. Probe (Pr) and primer (F: forward; R: reverse) sequences and assay parameters for detecting various amoeba taxa

\begin{tabular}{|c|c|c|c|c|c|}
\hline Amoebae & Probe/primer & Sequence $\left(5^{\prime}-3^{\prime}\right)$ & $\begin{array}{l}\text { Reaction } \\
\text { conc. (nM) }\end{array}$ & $\begin{array}{l}\text { Annealing } \\
\text { temp. }\left({ }^{\circ} \mathrm{C}\right)\end{array}$ & $\begin{array}{l}\text { Amplicon } \\
\text { length (bp) }\end{array}$ \\
\hline Nolandella spp. & $\begin{array}{l}\text { Nol-Pr } \\
\text { Nol-F } \\
\text { Nol-R }\end{array}$ & $\begin{array}{l}\text { AGA GCT TTA GCT TGC CC } \\
\text { CCG GTG AGG ATT CAG GAT } \\
\text { TGG CTG AAC ACG CTT ACC CT }\end{array}$ & $\begin{array}{l}250 \\
400 \\
400\end{array}$ & 63 & 61 \\
\hline Pseudoparamoeba sp. & $\begin{array}{l}\text { Pse-Pr } \\
\text { Pse-F } \\
\text { Pse-R }\end{array}$ & $\begin{array}{l}\text { CATCCTGTCCTGACTTGT } \\
\text { CCA GCA ATG GAA CGC TTT GT } \\
\text { CAC CAA GTG TCC CTC TAA GAA GTT AA }\end{array}$ & $\begin{array}{l}250 \\
300 \\
300\end{array}$ & 60 & 67 \\
\hline Paramoeba eilhardi & $\begin{array}{l}\text { ParE-Pr } \\
\text { ParE-F } \\
\text { ParE-R }\end{array}$ & $\begin{array}{l}\text { TCGTTTTCATTCGTCAGAAT } \\
\text { CAT CCT TTA TGG GGA GGG TTC TA } \\
\text { GAA CAG TTT TAA CCG AAG TTG CAA C }\end{array}$ & $\begin{array}{l}125 \\
300 \\
900\end{array}$ & 60 & 111 \\
\hline Vannellida C2 & $\begin{array}{l}\text { VanC2-Pr } \\
\text { VanC2-F } \\
\text { VanC2-R }\end{array}$ & $\begin{array}{l}\text { ATC GTG AGG ATA TAG TTG CTT } \\
\text { CGC TCC TAC CGA TTG GAT GT } \\
\text { CGA CTT CTC CTT CCT CTA GAT GTT ATG }\end{array}$ & $\begin{array}{l}100 \\
300 \\
300\end{array}$ & 60 & 116 \\
\hline Vannellida C3 & $\begin{array}{l}\text { VanC3-Pr } \\
\text { VanC3-F } \\
\text { VanC3-R }\end{array}$ & $\begin{array}{l}\text { ATA TCC TCT TTA GCA CCT TTG A } \\
\text { CCA GGG ATT AGA GGG AGA AAC A } \\
\text { CCC CCC AGA ATTT ATC TCA ATG }\end{array}$ & $\begin{array}{l}150 \\
300 \\
900\end{array}$ & 60 & 91 \\
\hline
\end{tabular}

run against each sample (Bruno et al. 2007). Samples were determined as positive detections if the average Ct of 2 or 3 technical replicates was lower than the limit of detection specific to each assay.

\subsection{Statistical analysis}

All graphics and analysis were performed in R version 3.5.2 (R Core Team 2018). To evaluate how spatial, temporal and pathological variables influenced $N$. perurans infection load, the $N$. perurans $18 \mathrm{~S}$ rRNA copy number was first $\log _{10}$ transformed after increasing all values by 1 to account for the zero values. To investigate the correlation between gill score and $N$. perurans abundance, a linear model was fitted. The mean $N$. perurans abundance with respect to time and site was compared using a 2-way ANOVA and then a Tukey post-hoc test to determine significant pairwise differences among sampling events. A paired $t$-test was used to compare the mean $N$. perurans abundance by site, the $N$. perurans prevalence by site and the mean gill score by site.

\section{RESULTS}

\section{1. qPCR assays design and optimisation}

After the design and optimisation of TaqMan qPCR assays specific to the chosen amoebae, the probe and primer sequences and reaction parameters were established as listed in Table 2. Results related to the primer and probe optimisation are available in Tables S1 \& S2 in the Supplement at www.int-res. com/articles/suppl/q011p405_supp.pdf.

\section{2. qPCR assays validation}

Each newly designed qPCR assay underwent a series of validation experiments to determine their performance using both plasmid DNA and amoeba DNA as template. The results of these experiments are summarised in Table 3 with reference to the supplementary material containing the raw data. Despite NPJ being a previously published assay (Downes et al. 2015), a new standard curve and limit of detection was generated so that it was specific to our qPCR conditions (i.e. machine, taq, plasmid DNA template, etc.). Additionally, the precision, reproducibility and specificity experiments were repeated for NPJ, to act as a benchmark assay.

All 6 assays generated a linear standard curve, indicated by the coefficient of determination $\left(\mathrm{R}^{2}\right)$ value close to 1 . The amplification efficiency varied between the assays, with the Pse being the most efficient at $99.98 \%$ and the ParE being the least at $65.41 \%$. The limit of detection is first presented in Table 3 as the mean $\mathrm{Ct}$ of the dilution which provided a $\mathrm{Ct}$ value for all 4 technical replicates. This value was then converted to 18S rRNA copies and shows that NPJ was the most sensitive assay, detecting up to $0.6618 \mathrm{~S}$ rRNA copies $\mu^{-1}$, while ParE was the least sensitive with a limit of detection equivalent to $787118 \mathrm{~S}$ rRNA copies $\mu^{-1}$. The final dilution 
Table 3. Summary of validation metrics for the 6 amoeba Taqman qPCR assays. LOD: limit of detection; CV: coefficient of variation; Nol: Nolandella spp.; Pse: Pseudoparamoeba sp.; ParE: P. eilhardi; VanC2: Vannellida species 2; VanC3: Vannellida species 3; NPJ: N. perurans

\begin{tabular}{|c|c|c|c|c|c|c|c|}
\hline & Nol & Pse & ParE & VanC2 & VanC3 & NPJ $\mathrm{S}$ & $\begin{array}{l}\text { Supplementary } \\
\text { reference }\end{array}$ \\
\hline Standard curve $\mathrm{R}^{2}$ & 0.998 & 0.990 & 0.996 & 0.996 & 0.998 & 0.998 & Fig. S1 \\
\hline Amplification efficiency (\%) & 82.23 & 99.98 & 65.41 & 72.82 & 98.28 & 99.21 & Fig. S1 \\
\hline Limit of detection $(\mathrm{Ct})$ & 36.37 & 38.36 & 36.53 & 37.21 & 37.73 & 38.73 & Table S3 \\
\hline Limit of detection (18S rRNA copies $\mu l^{-1}$ ) & 13.50 & 1.35 & 7871 & 39.25 & 1.09 & 0.66 & Table S3 \\
\hline Precision of LOD (mean \pm SD) & $36.44 \pm 0.57$ & $39.42 \pm 0.58$ & $35.96 \pm 0.57$ & $37.98 \pm 0.62$ & $35.98 \pm 0.62$ & $39.48 \pm 0.54$ & Fig. S2 \\
\hline Intra-assay variance (mean CV \%) & 0.81 & 1.02 & 2.09 & 1.01 & 1.45 & 0.53 & Table S4 \\
\hline Inter-assay variance (mean CV \%) & 1.06 & 1.35 & 2.19 & 1.31 & 1.72 & 0.88 & Table S4 \\
\hline
\end{tabular}

which determined the limit of detection was tested a further 20 times to determine the precision of the assay at a $95 \%$ confidence level. All precision data, apart from 2 outliers (Fig. S2), were close to the mean value for each assay, indicating low variability (all $\mathrm{SD}<0.7)$.

The final 2 values in Table 3 refer to the reproducibility of each assay between technical replicates (intra-assay variance) and between different days (inter-assay variance) and is expressed as the coefficient of variation (CV). The mean intra-assay variation of all assays ranged between $0.53 \%$ for the NPJ assay and $2.09 \%$ for the ParE assay. In contrast, the mean inter-assay variation of all assays ranged between $0.88 \%$ for NPJ and $2.19 \%$ for ParE, which were again the best and worst performers respectively. A 1-way ANOVA further indicated there was no significant difference between the assays results conducted on 3 different days, as all p-values were $>0.05$ (Nol: 0.90, Pse: 0.99, ParE: 0.96, VanC2: 0.96, VanC3: 0.99, NPJ: 0.72).
Initially, all the newly designed probes and primers were deemed theoretically specific as they had no complete matches to existing reference sequences in the BLASTn database. The assays specificity was further tested against DNA samples from clonal amoeba cultures and specific plasmid DNA in the cases where no amoeba DNA-positive control was available. A positive detection was defined by a mean $\mathrm{Ct}$ value lower than the limit of detection and is marked in bold in Table 4. All assays appeared to be species-specific in terms of the amoeba strains against which they were tested, except for NPJ and Nol. NPJ had some cross-reactivity with Pseudoparamoeba sp., while Nol amplified 2 Nolandella species, the ATCC Nolandella sp. strain as well as the Nolandella culture it was designed to detect. The Nol assay was therefore defined as genus-specific, rather than species-specific.

To assess the presence of amplification inhibitors in gill swab DNA sourced from Tasmanian salmon farms, 5 samples were diluted, spiked with the same

Table 4. Specificity of the 6 qPCR assays (see Table 3 for abbreviations) determined by testing each assay against various amoeba DNA samples listed as taxa (strain). Positive detections are indicated in bold. -: undetected

\begin{tabular}{|c|c|c|c|c|c|c|}
\hline DNA samples & Nol & Pse & ParE & VanC2 & VanC3 & NPJ \\
\hline Neoparamoeba perurans (MP2) & 41.42 & - & 38.36 & 37.51 & - & 23.03 \\
\hline Vexillifera sp. (MX6) & 39.66 & - & - & - & 41.78 & - \\
\hline Pseudoparamoeba sp. (MX1) & 37.66 & 22.20 & - & 37.42 & 39.42 & 35.88 \\
\hline Vannella sp. (MV3) & 36.74 & - & - & 37.62 & - & - \\
\hline Vannella sp. (MV4) & - & - & - & - & - & - \\
\hline Vannella sp. (MV5) & 38.68 & - & - & - & - & - \\
\hline Nolandella sp. (MX5) & 24.50 & - & - & - & - & - \\
\hline Neoparamoeba pemaquidensis (ATCC 50172) & - & - & - & - & - & - \\
\hline Acanthamoeba jacobsi (ATCC 30732) & - & - & - & - & - & - \\
\hline Nolandella sp. (ATCC PRA-27) & 24.15 & - & - & - & - & - \\
\hline Hartmannella vermiformis (ATCC 30967) & - & - & - & - & - & - \\
\hline ParE plasmid & - & - & 15.27 & - & - & - \\
\hline VanC2 plasmid & - & - & - & 13.53 & - & - \\
\hline VanC3 plasmid & - & - & - & - & 6.90 & - \\
\hline No template & - & - & - & - & - & - \\
\hline
\end{tabular}


amount of plasmid DNA and then tested in triplicate. No inhibition was detected because amplification remained consistent across the dilution series (Fig. S3).

\subsection{Survey of amoeba prevalence and abundance}

Of the 6 amoeba species surveyed on the gills of farmed Atlantic salmon, Neoparamoeba perurans was the most prevalent (Fig. 2). N. perurans was dominant across both temporal and spatial factors, except at 1 site at a single time point. Atlantic salmon held at Killala during May 2017 were not colonised by detectable levels of $N$. perurans; rather, Nolandella spp. was highly prevalent, infecting $92 \%$ of salmon which had an average gill score of 0.225 (Fig. 2A). Except for this sampling event, Nolandella spp. were not detected in any other gill samples. Pseudoparamoeba sp. and the 2 Vannellida species were detected on the gills of a relatively small proportion of Atlantic salmon compared to $N$. perurans and Nolandella spp., and these few instances were not correlated with temporal or pathological factors. The remaining species, Paramoeba eilhardi, was not detected on any Atlantic salmon gills. In terms of the amoeba community on individual fish, non-N. perurans amoeba species were detected on 41 Atlantic salmon throughout the entire survey, and of these, 8 individual fish tested positive for $N$. perurans and 1 other amoeba species. There were no individual fish that tested positive for $\geq 3$ amoeba species colonising the gills.

The relative abundance of $N$. perurans was further analysed to explore correlations between gross gill pathology, farm site and time points. The relative abundance of $N$. perurans increased with increasing gill score, indicated by the upward trend of the regression line fitted to Fig. 3A. Although this model was significant $\left(\mathrm{p}=2.2 \times 10^{-16}\right)$, only $25 \%$ of the variability in $N$. perurans abundance could be explained by gross gill pathology $\left(\mathrm{R}^{2}=0.247\right)$. In terms of temporal and spatial factors (Fig. 3B), there were differences by site $\left(p=9.57 \times 10^{-5}\right)$, but when considering both, there was a significant difference between May 2017 and Aug 2017 ( $\mathrm{p}=8 \times 10^{-7}$ ), Nov 2017 and Aug 2017 $\left(p=5 \times 10^{-6}\right)$ and May 2017 and Feb $2018(p=0.004)$. The trend in $N$. perurans abundance across site and time (Fig. 3B) also reflected the fluctuations in N. perurans prevalence (Fig. 2), in that the number of Atlantic salmon infected with $N$. perurans increased with the $N$. perurans load on the gills. Abundance also aligned with the severity of gross gill pathology, shown by the average gill scores marked on Fig. 2 .

When considering site-based differences alone, the overall $N$. perurans infection prevalence significantly differed $\left(\mathrm{p}=1.374 \times 10^{-6}\right)$ with $47.4 \%$ of salmon sam-
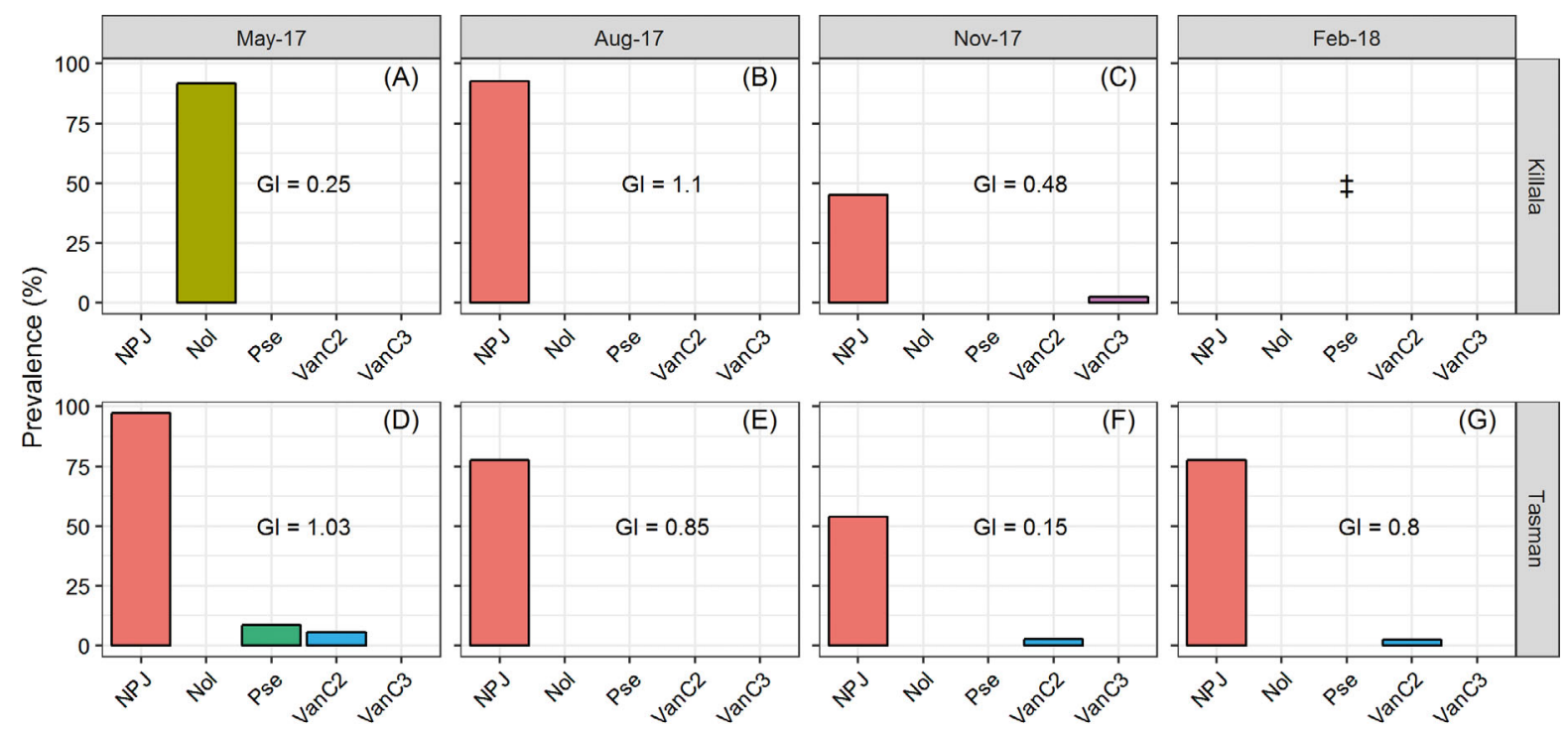

N. perurans (NPJ) $\square$ Nolandella (Nol)

Pseudoparamoeba sp. (Pse)

Vannellida C2 (VanC2)

Vannellida C3 (VanC3)

Fig. 2. (A-G) Prevalence of Atlantic salmon gills that were colonised by N. perurans (NPJ), Nolandella spp. (Nol), Pseudoparamoeba sp. (Pse) and Vannellida (VanC2, VanC3) at each farm site (Killala, Tasman) over a year. P. eilhardi was not included because no Atlantic salmon tested positive for the amoeba species. The average gill score (gill index [GI]) for each site and each time point is marked in the respective panels. The Feb 2018, Killala sampling event marked with $\ddagger$ is blank because no samples could be collected 

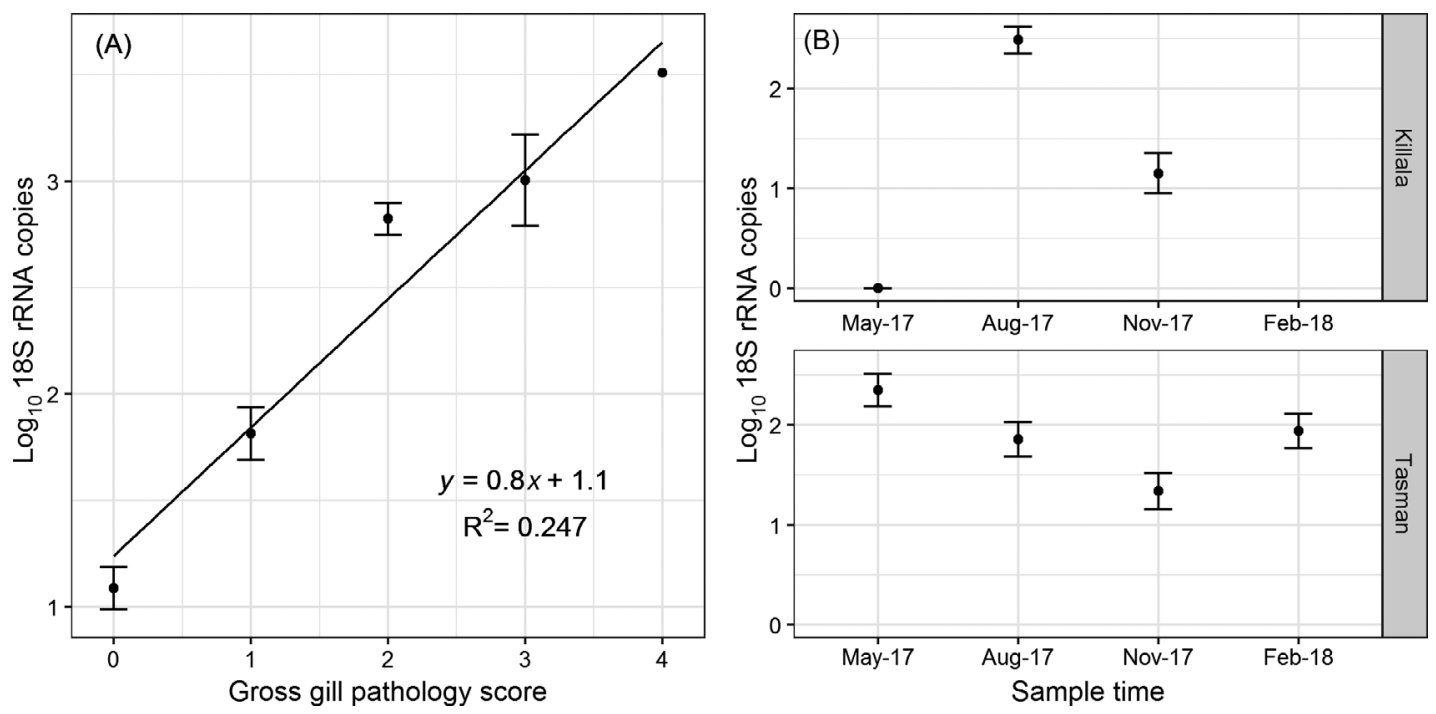

Fig. 3. Relative abundance of $N$. perurans on Atlantic salmon gills express as the mean \pm SE of $18 \mathrm{~S}$ rRNA copies with respect to (A) AGD gross gill pathology (gill score) quantified according to Taylor et al. (2009) and (B) farm site and sample time. The Feb 2018 Killala sampling is blank because no samples could be collected

pled at Killala infected compared to $76.1 \%$ at Tasman. The abundance of $N$. perurans on the gills was also significantly different between the sites $(p=$ $2.232 \times 10^{-5}$ ), as salmon at Killala had a lower average $N$. perurans load of $1.213 \log _{10} 18 \mathrm{~S}$ rRNA copies compared to Tasman at $1.871 \log _{10} 18 \mathrm{~S}$ rRNA copies. There was no significant difference in severity of gross gill pathology with respect to site (mean gill score Killala $=0.6$, Tasman $=0.69, \mathrm{p}=0.366$ ).

\section{DISCUSSION}

Five qPCR assays were designed to detect amoeba species previously isolated from AGD-affected Atlantic salmon Salmo salar and then used in a spatial-temporal survey to infer the potential role these species play alongside Neoparamoeba perurans in AGD of farmed Atlantic salmon. $N$. perurans was by far the dominant species colonising Atlantic salmon gills (Fig. 2.), and their abundance was related to gross pathology (Fig. 3A), farm sites and time points throughout the year (Fig. 3B). There were very few detections of the 5 non- $N$. perurans species apart from Nolandella spp. which was dominant at 1 site (Killala) during 1 sample time (May 2017) (Fig. 2A). Significantly, this is the first molecular-based study to investigate the ecology of multiple amoeba species in association with AGD and shows that, although the gills of farmed seawater Atlantic salmon subjected to a freshwater treatment regime are colonised with a diverse Amoebozoan community (English et al.
2019), N. perurans dominates this ecological niche, consistent with its documented role in AGD pathology (Crosbie et al. 2012).

As gross gill pathology became more severe, $N$. perurans abundance was positively correlated (Fig. 3A). Although this linear relationship was expected, the amount of variation in $N$. perurans abundance, expressed as 18S rRNA copies, across each gill score was not anticipated. A positive relationship between agent abundance and gross gill pathology (gill score 1 to 4 ) has previously been demonstrated with a small number of gill swabs from farmed Tasmanian salmon $(\mathrm{n}=32)$ (Bridle et al. 2010). This previous experiment retrieved a much tighter association with an $\mathrm{R}^{2}$ of -0.998 , compared to the model from the present study where only $25 \%$ of the variability in $N$. perurans abundance could be explained by gill pathology $\left(R^{2}=0.247\right)$. The increased unexplained variability could be reflective of the use of a different $N$. perurans-specific assay or variation in swabbing technique at each sampling event. It could also be because our study swabbed salmon across a number of time points at 2 different sites, as opposed to a singular sampling event, showing that $N$. perurans abundance and AGD progression was responsive to some site-based and seasonal variables.

From a commercial perspective, it is useful to understand whether particular farm sites produce fish with less severe AGD. The 2 farm sites in this survey were chosen based on hypothetical differences in terms of $N$. perurans infection prevalence and load due to the contrasting environmental condi- 
tions and the observation that lower salinity reduces $N$. perurans abundance (Wright et al. 2017). The Killala site is exposed to more freshwater runoff, attributed to its location in the Huon Estuary, while the Tasman farm is more oceanic (Fig. 1). Indeed, we did find Killala had an overall lower percentage of Atlantic salmon infected with $N$. perurans and a lower mean $N$. perurans load compared to Tasman. However, there was no difference in severity of gross gill pathology between the 2 sites, with an overall mean gill score of 0.6 at Killala and 0.69 at Tasman $(p$-value $=0.366)$. It appears that fish stocked at the Tasman lease are more likely to be infected with $N$. perurans, but these differences do not impact the severity of gross gill pathology at the 2 sites when considering gross pathology alone. However, it is likely a significant difference in AGD severity would become evident over more sampling events and with more sensitive methods for scoring pathology, such as histopathology (Adams \& Nowak 2003).

Temporal differences in $N$. perurans infection prevalence and load also differed by location. At the Tasman lease, the highest $N$. perurans infection prevalence and load was recorded in May 2017 and Feb 2018 and the lowest in Nov 2017 (Fig. 3B). At the Killala lease, the highest was recorded in Aug 2017 and the lowest in May 2017. Although there were too few sampling events to draw conclusions on seasonal variation from our survey, the temporal trends at the Tasman lease broadly reflect past seasonal trends recorded in AGD-affected farmed Tasmania Atlantic salmon (Clark \& Nowak 1999). AGD prevalence has been shown to peak in summer, followed by a second spike in autumn, and this also correlated with higher water temperature and salinity (Clark \& Nowak 1999). Similarly, an in vitro growth optimisation study found peak $N$. perurans growth occurs at $15^{\circ} \mathrm{C}$ and a salinity of 35 ppt (Collins et al. 2019). However, the Killala lease did not reflect that higher Tasmanian water temperatures support the highest $N$. perurans infection prevalence and load. Instead, the time point with the coolest water temperature of $11.9^{\circ} \mathrm{C}$, Aug 2017, had the highest $N$. perurans infection prevalence $(92.5 \%)$ and load at this lease. This observation supports that $N$. perurans are very adaptable to environmental parameters (Lima et al. 2016, Collins et al. 2019) and infectious over a range of temperatures and salinities (Clark \& Nowak 1999).

The reasons for the dichotomy between Nolandella spp. and N. perurans prevalence in May 2017 (Fig. 2A,D) is speculative. One explanation could relate to exposure time to $N$. perurans. The Atlantic salmon sampled at Killala in May 2017 were trans- ferred to sea $<1$ mo before sampling and had never been treated for AGD ( 2 to $3 \mathrm{~h}$ freshwater bath), while all other fish swabbed during the survey were at sea for $\geq 3 \mathrm{mo}$ and had undergone freshwater treatments. The Killala site had also been fallowed for 7 mo prior to restocking, and it is possible that $N$. perurans density within the environment decreased over this fallowing period. Then, in the absence of $N$. perurans, other amoeba species filled this niche. Moreover, Nolandella sp. strain MX5 (English et al. 2019) showed tolerance to salinity $<35$ ppt during our in-house culturing. Further research could investigate whether Nolandella spp. are specific to sites with more estuarine conditions or their presence is attributed to the absence of $N$. perurans.

Further research should also investigate whether the presence of Nolandella spp. is either reflective of healthy Atlantic salmon gills, simply a commensal bystander or a potential player in the early stages of gill disease. For instance, a similar amoebic disease, nodular gill disease (NGD), which affects freshwater salmonids, is proposed to have a multi-amoeba aetiology, and different amoeba species are hypothesised to influence different phases of disease development (Dyková et al. 2010, Dyková \& Tyml 2016). The Atlantic salmon that tested positive for Nolandella spp. and negative for $N$. perurans had an average gill score of 0.225 , which was a relatively low level of AGD-like gross gill pathology compared to the other sampling events. The gross AGD-like lesions were recorded with the Taylor et al. (2009) scoring method and were not confirmed by histology because destructive sampling did not suit working alongside the commercial farm. Because histology was not used to confirm an AGD diagnosis, it is possible some gross gill lesions could be unrelated to AGD. The use of histology in conjunction with qPCR should be considered in future surveys aiming to identify relationships between specific amoeba taxa and gill pathology, or more specifically, in future investigation into the significance of Nolandella spp. in relation to AGD.

Pseudoparamoeba sp., the 2 Vannellida species and Paramoeba elhardi, are minor players in the farmed salmon gill Amoebozoa community on the east coast of Tasmania. With so few detections, no strong spatial, temporal or pathological correlations could be established for the majority of the non-Neoparamoeba species. Our findings do not corroborate an earlier study which is the only other published survey that attempted to associate AGD pathology with a variety of protozoans (Bermingham \& Mulcahy 2006). The Ireland-based survey used histological observations 
to conclude that abundance of amoebae other than Neoparamoeba spp., Ichthyobodo-like flagellates and trichodinid ciliates correlated with gill pathology, while the abundance of Neoparamoeba spp. did not. This differs from our findings, where the abundance of Neoparamoeba sp. correlated with increased gross gill pathology, while the abundance of nonNeoparamoeba did not. Indeed, the contrasting results could be due to different locality, the possible mistaken documentation of complex gill disease rather than AGD (Herrero et al. 2018), or the study being conducted before species-specific molecular tools were available, relying instead on histology of gills. This technique is vulnerable to inaccurate documentation of amoeba community composition due to loss of amoebae during fixation, difficulty identifying protozoans in histology sections, and the limited sample size from each gill basket (1 section from 1 gill arch). Since this early study, molecular diagnostics identified $N$. perurans as the causative agent in the earliest outbreaks of AGD in Ireland which were preserved in histological samples (Downes et al. 2018).

The absence of $P$. eilhardi detections suggests either the isolation of this species documented by English et al. (2019) was a one-off occurrence or the qPCR assay was not sensitive enough. The latter reason is most likely, as the $P$. eilhardi assay performed relatively poorly in terms of amplification efficiency, limit of detections and intra- and inter-assay variance (Table 3). In comparison, the other 4 newly designed qPCR assays performed markedly better in the validation experiments and were of similar efficiency to the previously published $N$. perurans (NPJ) assay (Downes et al. 2015). The only concern with the remaining assays was that NPJ and Nol had some cross reactivity with non-target species. However, the NPJ assay only narrowly returned a positive result when tested against a high concentration of Pseudoparamoeba DNA, and the Nol assay was cross reactive with a species from the same genus and was thus deemed genus-specific, not species-specific. We therefore believe this lower specificity would not have affected the final conclusions. Hence, the qPCR assays, excluding perhaps the $P$. eilhardi assay, were considered fit for purpose, accurately quantifying their respective amoeba in the survey gill swabs.

\section{CONCLUSION}

While a diversity of amoebae colonise the gills of farmed Atlantic salmon Salmo salar with AGD, Neoparamoeba perurans is the dominant species, and increasing $N$. perurans load on the gills correlates with increasing AGD pathology. However, despite $N$. perurans being the dominant species, there were times when they could not be detected and Nolandella spp. were highly prevalent on gills with low levels of gross gill pathology. Further research should investigate whether Nolandella spp. frequently colonises farmed Atlantic salmon gills and whether they are parasitic or commensal.

Acknowledgments. The authors acknowledge Tassal Operations Pty Ltd for their support of the project, particularly Ben Morrisby, Eduardo Canosa, Christine Huynh and Bradley Evans for their technical assistance. We also thank Ben Maynard for sample collection and Megan Rigby for the valuable suggestions on the manuscript. This work was supported by CSIRO Aquaculture and The Crawford Fund (Crawford-inQueensland 2016 Post Graduate Research Award).

\section{LITERATURE CITED}

Adams MB, Nowak BF (2001) Distribution and structure of lesions in the gills of Atlantic salmon, Salmo salar L., affected with amoebic gill disease. J Fish Dis 24:535-542

Adams MB, Nowak BF (2003) Pathology of amoebic gill disease in Atlantic salmon (Salmo salar L. ). J Fish Dis 26: 601-614

*Bermingham ML, Mulcahy MF (2006) Microfauna associated with amoebic gill disease in sea-farmed Atlantic salmon, Salmo salar L., smolts. J Fish Dis 29:455-465

* Bermingham ML, Mulcahy MF (2007) Neoparamoeba sp. and other protozoans on the gills of Atlantic salmon Salmo salar smolts in seawater. Dis Aquat Org 76:231-240

Bridle AR, Crosbie PB, Cadoret K, Nowak BF (2010) Rapid detection and quantification of Neoparamoeba perurans in the marine environment. Aquaculture 309:56-61

* Bruno D, Collet B, Turnbull A, Kilburn R and others (2007) Evaluation and development of diagnostic methods for Renibacterium salmoninarum causing bacterial kidney disease (BKD) in the UK. Aquaculture 269:114-122

*Bustin SA, Benes V, Garson JA, Hellemans J and others (2009) The MIQE guidelines: minimum information for publication of quantitative real-time PCR experiments. Clin Chem 55:611-622

Clark A, Nowak BF (1999) Field investigations of amoebic gill disease in Atlantic salmon, Salmo salar L., in Tasmania. J Fish Dis 22:433-443

Collins C, Hall M, Fordyce MJ, White P (2019) Survival and growth in vitro of Paramoeba perurans populations cultured under different salinities and temperatures. Protist 170:153-167

* Crosbie PBB, Bridle AR, Cadoret K, Nowak BF (2012) In vitro cultured Neoparamoeba perurans causes amoebic gill disease in Atlantic salmon and fulfils Koch's postulates. Int J Parasitol 42:511-515

* Downes JK, Henshilwood K, Collins EM, Ryan A and others (2015) A longitudinal study of amoebic gill disease on a marine Atlantic salmon farm utilising a real-time PCR assay for the detection of Neoparamoeba perurans. Aquacult Environ Interact 7:239-251

Downes JK, Collins EM, Morrissey T, Connor IO and others 
(2018) Confirmation of Neoparamoeba perurans on the gills of Atlantic salmon during the earliest outbreaks of amoebic gill disease in Ireland. Bull Eur Assoc Fish Pathol 38:42-48

Dyková I, Tyml T (2016) Testate amoeba Rhogostoma minus Belar, 1921, associated with nodular gill disease of rainbow trout, Oncorhynchus mykiss (Walbaum). J Fish Dis 39:539-546

* Dyková I, Kostka M, Wortberg F, Nardy E, Pecková H (2010) New data on aetiology of nodular gill disease in rainbow trout, Oncorhynchus mykiss. Folia Parasitol (Praha) 57: 157-163

Egan S, Gardiner M (2016) Microbial dysbiosis: rethinking disease in marine ecosystems. Front Microbiol 7:991

English CJ, Tyml T, Botwright NA, Barnes AC, Wynne JW, Lima PC, Cook MT (2019) A diversity of amoebae colonise the gills of farmed Atlantic salmon (Salmo salar) with amoebic gill disease (AGD). Eur J Protistol $67: 27-45$

Evans DH (2005) The multifunctional fish gill: dominant site of gas exchange, osmoregulation, acid-base regulation, and excretion of nitrogenous waste. Physiol Rev 85: 97-177

Feehan CJ, Johnson-Mackinnon J, Scheibling R, LauzonGuay JS, Simpson A (2013) Validating the identity of Paramoeba invadens, the causative agent of recurrent mass mortality of sea urchins in Nova Scotia, Canada. Dis Aquat Org 103:209-227

Fringuelli E, Gordon AW, Rodger H, Welsh MD, Graham DA (2012) Detection of Neoparamoeba perurans by duplex quantitative Taqman real-time PCR in formalin-fixed, paraffin-embedded Atlantic salmonid gill tissues. J Fish Dis 35:711-724

Gjessing MC, Thoen E, Tengs T, Skotheim SA, Dale OB (2017) Salmon gill poxvirus, a recently characterized infectious agent of multifactorial gill disease in freshwaterand seawater-reared Atlantic salmon. J Fish Dis 40: 1253-1265

Haugland GT, Olsen AB, Rønneseth A, Andersen L (2017) Lumpfish (Cyclopterus lumpus L.) develop amoebic gill disease (AGD) after experimental challenge with Paramoeba perurans and can transfer amoebae to Atlantic salmon (Salmo salar L.). Aquaculture 478:48-55

Herrero A, Thompson KD, Ashby A, Rodger HD, Dagleish

Editorial responsibility: Kate Hutson, Nelson, New Zealand
MP (2018) Complex gill disease: an emerging syndrome in farmed Atlantic salmon (Salmo salar L.). J Comp Pathol 163:23-28

Howard T (2001) Paramoebiasis of sea-farmed salmonids in Tasmania-a study of its aetiology, pathogenicity, and control. PhD dissertation, University of Tasmania, Launceston

K Lima PC, Taylor RS, Cook M (2016) Involvement of contractile vacuoles in the osmoregulation process of the marine parasitic amoeba Neoparamoeba perurans. J Fish Dis 39: 629-633

*Mitchell SO, Rodger HD (2011) A review of infectious gill disease in marine salmonid fish. J Fish Dis 34:411-432

Oldham T, Rodger H, Nowak B (2016) Incidence and distribution of amoebic gill disease (AGD) - an epidemiological review. Aquaculture 457:35-42

* Purcell MK, Getchell RG, McClure CA, Garver KA (2011) Quantitative polymerase chain reaction (PCR) for detection of aquatic animal pathogens in a diagnostic laboratory setting. J Aquat Anim Health 23:148-161

R Core Team (2018) R: a language and environment for statistical computing. R Foundation for Statistical Computing, Vienna

Staroscik A (2004) Calculator for determining the number of copies of a template. https://cels.uri.edu/gsc/cndna.html (accessed Jan 2017)

* Taylor R, Muller W, Cook M, Kube P, Elliott N (2009) Gill observations in Atlantic salmon (Salmo salar, L.) during repeated amoebic gill disease (AGD) field exposure and survival challenge. Aquaculture 290:1-8

Thermo Fisher (2010) Applied Biosystems Custom Primer \& TaqMan Probes. https://www.thermofisher.com/de/de/ home/life-science/oligonucleotides-primers-probesgenes/applied-biosystems-custom-primers-probes.html (accessed Dec 2016)

*Wright DW, Nowak B, Oppedal F, Bridle A, Dempster T (2017) Free-living Neoparamoeba perurans depth distribution is mostly uniform in salmon cages, but reshaped by stratification and potentially extreme fish crowding. Aquacult Environ Interact 9:269-279

Y Young ND, Crosbie PBB, Adams MB, Nowak BF, Morrison RN (2007) Neoparamoeba perurans n. sp., an agent of amoebic gill disease of Atlantic salmon (Salmo salar). Int J Parasitol 37:1469-1481

Submitted: April 2, 2019; Accepted: July 4, 2019

Proofs received from author(s): August 18, 2019 